discharged, her condition being about the same as described in the last note, requiring morphia nearly every night. From the present house-surgeon, Mr. Payne, I now hear that the patient was readmitted in September, and had the fibula gouged, after which she was almost well, having only slight pain in the tibia. The measurements of the ankle were interesting. On Nov. 6th, 1880, the right measured $10 \mathrm{in}$. in circumference, as against $8 \mathrm{in}$. for the left; on Feb. 17th, 1881, the right measured $9 \frac{1}{2}$ in. ; April 4th, 9 in. ; showing a decrease of 1 in. On admission some trials were made with Sequin's thermometer to ascertain the hottest part of the affected ankle, with the result that over the fibula $6^{\circ}$ were registered, against $42^{\circ}$ over the inner malleolus, and $33^{10}$ in front of the ankle.

CASE 2.-E. B —, aged twenty-one years, weaver, was admitted on March 20tb, 1881, under the care of Mr. Hughes. Eight years ago she sprained her left ankle and was laid up one year with it. She got better, but still had pain in it after a long journey. Two years ago the pain began to get worse, which she attributed to having to stand longer hours at her work. Had worked up to the time of admission, but often only two or three hours a day. Patient was to all appearance in perfect health. The lower two inches of tibia and fibula of the left foot were enlarged, the tibia being quite half as large again as on the right side. Measurement gave one inch increase, and Sequin's thermometer showed $\frac{3^{\circ}}{4}$ greater heat. The pain was so severe as to require morphia every night. As rest in $b \in d$ and connterirritation produced no improvement after a month's trial, it was decided to trephine both tibia and fibula, as in the previous case. After the oreration the patient was quite free from pain, and when last seen, seven weeks later, there had been no return.

CASE 3.-H. W- aged sixteen, piercer in a cotton-mill. Ankle has been bad seven weeks, but the pain did not commence till a fortnight Jater. Can give no cause for it. The pain is severe, but only at night. The patieut is fairly healthy looking, but has enlarged submaxillary glands. The lower three inches of tibia of left side are enlarged to nearly double, and somewhat tender to pressure; fibula is also enlarged, but not to the same extent. Sequin's thermometer showed $1^{\circ}$ to $1 \frac{1}{2}^{\circ}$ more warmth for the affected ankle. On March 29th, 1881, an incision was made antiseptically along inner malleolus down to the bone. After the operation the patient still complained of pain, thongh it was not so bad. April 26th: Measurements showed a circumference two inches in excess of the right. On April 30th an abscess appeared over the lower end of the fibula, which was subsequently opened and healed without any trouble. On June 8th there was a diminution of half an inch in the size of the ankles; no pain. By June 27 th he was able to walk without any pain. The subsequent history, however, showed that the relief was only temporary. In November both boves were trephined, after which he was again free from pain.

Cases in which an abscess or abnormal cavity has been found, on trephining a bone for chronic disease, are not uncommon. Thus out of 34 cases that $I$ have been able to collect ${ }^{1}$ in which this operation had been performed, one of these two conditions was found in no less than 30 of the number, while in four only could no trace of either pus or cavity be seen ; of the 30 , pus was found in 22 , and a simple cavity in 8 . It is, of course, impossible in the cases I have reported to assert positively the absence of a minute abscess, as this might very well have been overiooked; still it must have been very small, as nothing of the kind was noticed during the operation, and no subsequent diacharge of pus took place. An interesting point in these cases seems to be the complete, though temporary, nature of the relief obtained from sinply incising the periosteum; this is, I think, to be attributed to the transudation, which takes place through the bone, between the medullary cavity and the exterior; this would relieve the tension inside, but would ceace as soon as the surface became covered with granulations. Whether any operation short of trephining would have given sufficient relief is doubtful, and to judge from the first case it is probable that linear osteotomv, as recommended by Mr. Erichsen, would have been only of temporary service.

One point in which these cares differ from those that I have seen reported is the fact that both hones were affected, and to a searly equal degree, so as to require an operation on both. In only one were there any constitutional sym.

1 Reported by Gosselin, Duplay, Porter, Trélat, and Morris. ptoms that might be held to account for it; in both the others could the disease be traced to an injury. Bearing on this is a fact which I have noticed in compound wounds of the ankle-viz, that in all the cases I have seen, four in number, where the injury was limited to one side of the joint, there has occurred an abscess on the opposite side of the joint, and which in three healed without any troub!e. In the third case, given above, a simple incision over the tibia was followed by an abscess over the fibula. These cases are too few to allow of any conclusions being drawn; still $I$ think they point to some sort of relation existing between the two epiphyses, possibly through the blood or lymphatic channels, so that disturbances in the one may be transmitted to the other, similar perhaps to the periostitis which is so often seen as a result of osteo-myelitis.

London, N.W.

\section{REMARKS ON A CASE OF SO-CALLED HYSTERIA.}

\section{By J. B. FOOTNER, F.R.C.S. ENG.}

ABouT eight months ago, a well.nourished though somewhat ancmic young woman, unmarried, aged twenty-five, came to me for advice. She said that she had recently lost the use of her right thumb, and that her right arm was weaker than the left. She could not account in any way for this. About a year previously she had had sores on the right wrist, which, she said, took a very long time to heal. Apart from this her general health was fair, with the exception of some slight dyspeptic derangements. On examining the right arm, it was not found to he wasted as com. pared with the left; the muscles of the ball of the thumb were, however, dietinctly so, probably from disuse. I treated her by the application of the interrupted current to the muscles of the arm and thumb, and gave her arsenic internally. The arm and thumb soon began to improve under this treatment

About a month after her first visit she informed me that some sores similar to those which she had had a year ago had broken out on the back of her right hand and wrist. These sores presented a peculiar appearance, quite unlike any normal patbological process. They were about threequarters of an inch in length and one-quarter of an inch in breadth, longitudinally oval. They resembled very much the appearance produced by a blister with the cuticle en. tirely removed, and no sign of it left, but only a bare raw surface bathed in serum. There were next to no traces of inflammation. The sores were four in number, each of similar size, shape, and appearance, and in the long axis of the $\operatorname{limb}$. I ordered the application of zinc ointment.

She returned after a few days. The sores were no better, and had evidently been irritated. Having no doubt of this latter fact, it seemed to me the best plan would be to cover the sores with strapping extending continuously from below the situation of the sores to above them, as one straps an ulcer of the leg. This was done, and as she could not get at the sores they quickly healed. The strapping was continued for a fortnight afterwards. The ulcers were very soon reproduced, and also another of exactly similar appearance longitudinally over the insertion of the right deltoid. Strapping was again applied, and continued for four weeks, in the hope that by this time the patient would have forgotten about the sores. After this, for a week or two no ulcerations appeared; but soon she came again, with similar productions round the mouth just bordering on the lips. It was manifestly imposaible to apply strapping here, so lunar caustic was freely rubbed over the raw surfaces, hoping that the pain would act as a deterrent, and it did. She continued free from sores after this. Her right arm and thumb are now as strong as the left.

Quite recently she has reappeared with sores on the same wrist as before, for which I am adopting the same treatment. Had this been a hospital case I should probably have been able to discover how the sores are produced; but as she has a father a chronic invalid and a mother just recovering from hysterical paraplegia and aphonia (a bad nervous family history, be it remarked), it was useless to expect any assistance from them, and quite possibly they would not have believed that their daughter was the originator of the sores. I thiuk the best course was to endeavour to outwit the patient. 
A very interesting case at the North-West London Hospital of a somewhat similar character is reported by Dr. T. Colcott, Fox in The LanceT of Dec. 30th, 1882. In his case the girl confessed she had produced the sores partly with her nails, but mostly by continual rubbing with the tops of her fingers. It seems probable that the cause in my case is similar. Her right arm being weak, it can be readily imagined that she would use her left arm to produce these phenomena. She is not naturally left-handed.

Tunbridge Wells.

\section{SCARLET FEVER IN ITS RELATION TO THE PUERPERAL STATE.}

BY J. T. BURGESS, L.R.C.P., L.R.C.S. EDIN.

THE two following cases are interesting, and, I trust, worthy of record as illustrating a connexion between the scarlet and puerperal fevers. They at the same time throw some light upon the questions relating to the period of incubation and to the vitality of the contagious principle of the former disease. Lastly, they painfully demonstrate the fearful responsibility that devolves upon the medical practitioner towards his lying-in patients during the time he is in attendance upon scarlatinal cases.

On Nov, 20th, 1882, Mrs. A—, aged twenty-two, residing temporarily in an isolated cottage in a sparsely populated district, was delivered of a first child. The labour was tedious, and eventually was terminated with forceps, the child being stillborn. The mother, however, progressed satisfactorily until Saturday, Nov. 25th, when she became some what feverish, and complained of sickness and diary hœa. The next day (26th) the throat was sore, temperature $102^{\circ}$, and a slight rash was noticed on the upper parts of the body. This, during the next few days, became of a bright uniform scarlet, ran the usual course of a scarlatinal eruption, and was followed by free desquamation. Thus far no otber complication had arisen, but on Wednesday $(29 \mathrm{ch})$ a change for the worse occurred, the temperature, which had become almost normal, rose to $103^{\circ}$, the body became tympanitic, lochia slightly offensive, and intellect clouded. A hospital nurse was at once sent for, and the next day a consultation was beld with a neighbouring practitioner. Symptoms of exhanstion, however, snch as muttering delirium, picking at bedclothes, dry brown tongue, \&e., set in, and the tympanites increased. Patient sank on Sunday morning, Dec. 3rd, thirteen days after delivery, the temperature, as taken by the nurse shortly before death, having reached $106^{3}$. The origin of the poison in this case was at first difficult to discover. There had been no recent case of scarlet fever in the neighbourhood, and I failed to trace any expnsure to infection on the part of patient, nurse, or medical attendant. The foliowing is the only solution of the problem, which, after most careful inquiry, presents itself. The patient, upon marriage, was compelled to make temporary use of a cottage which had been empty for some time, and was condemned to be pulled down. The occupants of this cottage, who left it twelve months previously, had all suffered from scarlet fever, and the house had never been disinfected. The bedroom in which my patient was confined had to undergo a certain amount of preparation immediately hefore the event came off, and amongst other things, in order that the fireplace might be available, a quantity of old sacking was removed from the chimney. To this disturbance I am inclined to attribute the setting free of scarlatinal poison.

Whilst in atten ance upon the above, I was called upon, Dec. 1st, to attend M. G - This patient resided seven miles distant from the previous case. There had been no scarlet fever in her village, nor, as far as could be ascertained, could she have had communication with anyone suffering from that disease. M. G- was twenty-two years old, unmarried, and was prematurely delivered in the early morning of Dec. 2 nd of a small weakly child which died during the day. About 11 A $M$. the patient had a slight convulsive seizure, to which no importance was attached, as the girl had frequently shown symptoms of hystero-epilepsy during the two previous years. On Monday, Dec. 4th, however, a severe rigor took place in the afrernoon, followed hy a feverish state at night. A dose of castor oil was administered, after which a troublesome diarrhœe persisted for about a week On the 5th the throat became sore, and the feverish siate continued. On the 6 th I was called up at midnight, and found the patient delirious and more feverish the throat much inflamed, but no appearance of rash. On Saturday evening (8:h) the patient was decidedly worse. Irregular patches of dull red eruption were visible on various parts of the body, delirium had increased, the abdomen was greatly distended, and exhaustive symptoms were becoming prominent. During the next week there was very little change, except that desquamation manifested itself and went on freely. The urine, though at first scanty, was passed in fair quantity, but was slightly albuminous. The diarrhoea ceased, and it became necrssary to administer aperients. All this time the body remained much distended and painful in the hypogastric resi:n. On the 16 th the patient complained of pain in left side of thorax, which was easier on the $17 \mathrm{th}$, but worse on the $18 \mathrm{th}$, when the respiration was 38 , pulse $\mathbf{3 5 8}$, and temperature $103^{\circ}$. There was some dulness at the left base and a slight ruhbing sound above, probably pleuritic. The next two days saw symptoms somewhat better, but on the 21st there was a derided change for the worse. Pneumnnia and the greatly distended abdomen were together telling upon the respiratory function, respiration being 48 , pulse 174 , and temperature $1046^{\circ}$. The skin was pale, lips livid, and face anxious-looknng, though the delirium had passed away. After again $\mathbf{r}_{\mathrm{l}}$ llying on the 22nd, the patient sark from exhaustion on the 25th. On the $17 \mathrm{ch}$, a younger sister in the same household, who had been in close atteudance upon the patient, became feverish. On the 18th rash appeared, accompanied with slight sore-throat, and during the next few days she passed through a mild attack of scarlatina.

That the foundation disease in hoth these puerperal cases was scarlet fever can scarcely admit of doubt. The clinical history of the first case was well nigh typical. and any shade of hesitation about the second was di wyersed by the appear. ance of the disease in the younger sister. Had this second case stood alone, the real nature of the foundation disease might possibly have been overlooken, owing to the irregularity of the eruption both as regards time and appearance, notwith. standing the presence of sore-thriat and subsequent desquamation. The more important complicatious appeared to take the form of serous inflammations, and to be exaggerations of the after-consequences rather than of the primary symptoms of the disease. If we accept the theory that the first case received its contagion from the cottage itself and on the day of confinement (Nov, 20tb), we find a period of five days to have elapsed before the first manifestations of symptoms. In the second case, supposing the medical attendaut to have conveyed the infection at the time of parturition, the period of incubation was only three days. In the young girl's case it is difficult to state any defiaite period of incuhation, since it is impossinle to fix the exact date upon whirh she received infection. In the absence of other explanation the first case tends to prove that the vitality of the scallininal germ may, under favourable circumstances, continue for at least twelve months, a period much beyond its usually allot ted span. It is needless to add that, as soon as the suspicion of the nature of the second case dawned upon me, I at once gave up attending puerperal cases aud crntinued to do so till a month after the death of the parient. During that time I thoronghly fumigated all clothing, instruments, \&c., and submitted myself frequently to disinfectint baths. I am thankfal to say that, on renewal of midwifery practice, no further calanity has occurred.

Spilsby, Lincolnshire.

The Sanitary Institute of Great Britain.The autumn congress for 1883 of this association will be held at Glasgow from the 25th to the 29th of September in the St. Andrews halls, under the presidency of Professor G. M. Humplry, F.R.S. The exhibition in connexion with the meeting will he open in the Burnbank Drill-hall from September 25 th to October $20 \mathrm{cb}$. The covgress rill be divided into the following sections :-(1) Santary Science and Preventive Medicine ; (2) Engineering and Architecture; and (3) Chemistry, Meteorology, and Geology. The President of the first, will be Profe-sor Gairduer, M.D., LL.D. of the second, Professor T. Roger Smith, F.R.I.B.A.; and of the third, Mr. K. Angus Smith, Ph D., F.R.S. On the 29th Dr. Alfred Carpenter will deliver an address to the working classes. The Conncil invite paners on subjects mentioned in the programme, and will be glad to receive the personal co operation and sipport of all who are interested in the diffusion of sanitary knowledge. 